\title{
Espraiamento urbano e periferização da pobreza na regiáo metropolitana de Sáo Paulo: evidências empíricas
}

Vanessa Nadalin. Instituto de Pesquisa Econômica Aplicada, Brasília, Brasil. Danilo Igliori. Universidade de São Paulo, São Paulo, Brasil.

RESUmo | A evolução urbana da Região Metropolitana de São Paulo, Brasil, entre 1960 e 2000, indica um processo de espraiamento urbano definido como o crescimento urbano desconcentrado, não denso e que deixa vazios dentro da mancha urbana. Para comprová-lo se propôs a construção de um índice de espraimento a partir da análise de mapas da área urbanizada, a evolução das densidades populacional e de empregos e a evolução dos gradientes de densidade. Seus determinantes são buscados em análise econométrica. Os resultados indicam que houve espraimento no período mais recente analisado e que esse fenômeno se dá a partir da ocupação das periferias por população de baixa-renda.

PALAVRAS-CHAVE | expansão urbana, crescimento urbano, periferia urbana, descentralização, morfologia urbana.

ABSTRaCt | The urban evolution of São Paulo Metropolitan Area, Brazil between the years of 1960 and 2000 indicates an urban sprawl process defined as leapfrogging, a not concentrated and not dense urban growth. To make evident its existence as an urban sprawl index it has been proposed an analyzing urban area maps, the evolution of population and jobs density and the evolution of density gradients. Its determinants are searched using econometric analysis. Results point out that there was urban sprawl in the most recent period of time and show the link between this phenomenon and the occupation of suburbs by low income families.

KEY WORDS | urban sprawl, urban growth, urban periphery, decentralization, urban morphology. 


\section{Introduçáo}

São Paulo encontra-se no rol das grandes metrópoles, aquelas nas quais houve grande explosão populacional recente, e hoje ocupa a posição de segunda maior cidade da América Latina, atrás apenas da cidade do México (Instituto Brasileiro de Geografia e Estatística [IBGE], 2011; Instituto Nacional de Estadística y Geografía [INEGI], 2011). Como agravante ao rápido crescimento vivenciado na segunda metade do século $\mathrm{xx}$, enfrenta problemas relacionados à pobreza e à desigualdade, que adquirem características específicas no contexto da grande metrópole.

Além destes problemas, o crescimento do tecido urbano da Região Metropolitana de São Paulo pode ter acontecido de uma maneira específica, com espraiamento urbano. Este fenômeno pode ser indesejável se a área urbana não estiver crescendo naturalmente ${ }^{1}$, mas esteja crescendo mais do que deveria. Definimos como espraiamento urbano o crescimento urbano que é desconcentrado, não denso e que deixa vazios urbanos dentro da mancha urbana.

Uma característica relacionada ao espraiamento urbano é a periferização da população. Sejam as classes de baixa renda, sejam as de alta renda (atraídas por promessas de maior segurança), as famílias moradoras das zonas geograficamente periféricas tendem a despender maior tempo em seus deslocamentos pendulares (casa-trabalho) e a ter menos acesso à infraestrutura urbana. Em termos sociais o problema é relevante, pois a maior parte do movimento de periferização cabe à população de baixa renda, o que gera desigualdade social espacial.

Por outro lado, o esvaziamento de regióes centrais deixa subutilizadas áreas historicamente consolidadas, mais bem dotadas de infraestrutura e equipamentos culturais, universidades, parques, bibliotecas ou hospitais. Os custos de se levar infraestrutura às regiôes periféricas mais distantes, portanto, têm implicações que vão além da distância até as oportunidades de emprego. Além disso, se a cidade cresce mais do que deveria ${ }^{2}$, esses custos são inflacionados. E sofrem uma distorção na precificação, pois somente uma parte da população usufrui dos benefícios enquanto toda a população paga por boa parte que é fornecida pelo poder público.

Os dados da pesquisa de Origem-Destino (OD), realizada pela Companhia do Metropolitano de São Paulo-Metrô, refletem a periferização da população, indicando o aumento no número e extensão de viagens realizadas no modo individual. O total de quilômetros rodados ${ }^{3} \mathrm{em}$ todas as viagens para o ano de 1997 é de quase 300 milhóes, enquanto no ano de 2007 esse número é de mais de 700 milhôes $^{4}$, -um aumento de $266 \%$-. Já o número total de viagens no modo individual subiu $122 \%$. Sabemos

\footnotetext{
Discutiremos mais adiante a idéia do crescimento "exagerado", não "natural" das cidades.

Discutiremos mais adiante a idéia do crescimento não "natural”, das cidades que crescem mais do que deveriam.

3 Computamos a extensão de cada viagem como a distância euclidiana entre o centroide da zona de origem e o centroide da zona de destino.

4 O total de quilômetros rodados em 1997 é $286.280 .160 \mathrm{~km}$. Em 2007, 762.994 .798 km.

5 O total de viagens produzidas no modo individual para o ano de 1997 é de 31.432.205, enquanto para o ano de 2007 é de 38.234.971.
} 
como o número e a extensão das vias não crescem tão rápido quanto esses números, portanto, essa tendência contribuiu para um aumento dos congestionamentos.

Também é verificada a existência de efeitos negativos do crescimento urbano relacionados especificamente com o meio ambiente. Houve, por exemplo, desmatamento de cobertura vegetal entre os anos 1991 e 2000 como apontado pela Prefeitura do Município de Sáo Paulo (2002) no mapa de desmatamento do Atlas Ambiental do município de Sáo Paulo. A área vizinha aos dois grandes reservatórios de água da porção sul da RMSP (Represas Billings e Guarapiranga) vem sendo ocupada historicamente por loteamentos clandestinos e favelas, como relatado por Maricato (2001). Além da perda de cobertura vegetal, a maior impermeabilização do solo contribui para as enchentes e elevação das temperaturas urbanas. Ou seja, a expansão periférica gera impactos sobre o meio ambiente, causando problemas ambientais urbanos sentidos em toda a Região Metropolitana.

Colocados desta forma, alguns dos problemas urbanos da RMSP: periferização da população de baixa renda, aumento dos congestionamentos e ocupação de áreas ambientalmente vulneráveis, podem ser interpretados como indícios de que esta região metropolitana estaria passando por um processo de espraiamento urbano.

Assim, trazemos argumentos da teoria econômica sobre o tema e fazemos uma análise empírica, checando a existência do fenômeno na RMSP e buscando seus determinantes. No plano teórico apresentamos a lógica da estrutura urbana e o conceito de espraiamento como um crescimento urbano exagerado, ou seja, fruto de falhas de mercado. A parte empírica apresenta a proposta de um índice para mensuração do fenômeno entre as décadas de 1960 e 2000 e estatísticas descritivas e análise econométrica com dados censitários de 2000 que caracterizam a periferização da população de baixa renda.

\section{Monocentrismo, policentrismo e economias de aglomeração}

Para nossa discussão sobre espraiamento urbano o modelo de cidade monocêntrica, a síntese Alonso-Muth-Mills (АмM) a partir dos trabalhos de Alonso (1964). Mills (1967, 1972) e Muth (1969), é interessante, pois estabelece explicaçóes para a estrutura interna das cidades, especificamente no que diz respeito à fixação da fronteira entre as zonas rural e urbana e à densidade. Uma das principais intuiçóes da economia urbana para explicar a estrutura urbana, decorrente desse modelo, é a equivalência do valor da queda do aluguel ao aumento dos custos de transportes no orçamento das famílias que decidem morar mais longe do centro.

Brueckner (1987) refina esse modelo incorporando o lado da produção de habitaçóes com terra e capital como insumos. Dessa forma aparecem como variáveis do modelo a densidade e o raio da mancha urbana. Parece interessante considerar a metrópole de São Paulo como cidade fechada, na definição de Brueckner (1987) aquela com utilidade exógena, pois pelo seu tamanho e importância a influência das demais cidades na utilidade de reserva dos seus habitantes pode ser desconsiderada. Da solução para esse caso, chega-se que quanto maior a população da cidade, mais longe a fronteira e maior a densidade em todas as localizaçóes. Já um aumento no 
aluguel da terra encolhe a fronteira e também aumenta a densidade. Um aumento no custo marginal de transportes também aproxima a fronteira.

Para a análise do espraiamento será importante retomar esses resultados. Tanto a fronteira da cidade quanto as densidades têm impacto na nossa medida de espraiamento, pois esta será calculada com respeito ao crescimento da mancha urbana (mudança na fronteira de um momento no tempo para outro), e levará em conta quão compacto é esse crescimento (reflete a densidade). O modelo nos traz uma base teórica para conectar as outras variáveis consideradas como os custos de transportes e o tamanho da população a estas. Mas possui várias limitaçôes, como bem ilustrado por Anas, Arnott e Small (1998) e Brueckner (2000).

Particularmente importante para a compreensão do espraiamento urbano, o trabalho de Henderson e Mitra (1996) propóe um modelo que explica o surgimento de edge cities $^{6}$, adaptando o modelo de Fujita e Ogawa (1982). Nesta adaptação, os autores permitem que haja interação (comunicação) entre as firmas, com economias de escala externas às firmas, economias de aglomeração. Existem agentes grandes, que decidem ao longo de uma história, e que levam em conta custos fixos para a construção de um novo centro de emprego. Glaeser e Kahn (2004) interpretam o resultado desse modelo para a análise do espraiamento tanto nos fatores que influenciam na distância entre os centros, como nos determinantes da extensão da urbanização. Esses autores chegam à conclusão de que quanto maior os custos fixos da infraestrutura (para construir um subcentro), menor o espraiamento. Quanto maior o parâmetro que mede as economias de aglomeração (opostas às oportunidades de comunicaçáo dadas pela tecnologia de informação), menor o espraiamento.

\section{Formas de mensuração e definição do espraiamento urbano}

Como este será o conceito em que focaremos a análise da evolução da área urbanizada em São Paulo, cabe esclarecer a definição e possíveis formas de mensuração do espraiamento. Daremos início mencionando as diferentes definiçôes, para em seguida apresentar as dimensóes do fenômeno que podem ser mensuradas. A literatura sobre o tema provém quase inteiramente dos Estados Unidos, onde o termo utilizado é urban sprawl. Parece simples e suficientemente fiel a tradução para "espraiamento urbano", no entanto cabe mencionar como o termo vem sendo utilizado naquele país. A intensificação do uso do termo coincide com a mudança para o padrão atual e predominante de urbanização. Assim, uma definição utilizada por urbanistas e planejadores urbanos norte-americanos é: urbanização em baixas densidades, não planejada, dependente do automóvel, com alternativas construtivas homogêneas e esteticamente desagradáveis (Knaap \& Talen, 2005).

Em Anas, Arnott e Small (1998), o termo é mencionado como referente ao crescimento urbano que deixa espaços náo utilizados em seu interior (leapfrogging). Os vazios poderiam até ser benéficos, se urbanizados no futuro a uma densidade

6 As edge cities são um fenômeno diferenciado da periferização de empregos e famílias. São cidades próximas a grandes centros, de uso misto, com todas as funçôes de uma cidade. São criadas por grandes incorporadores da iniciativa privada. Em São Paulo, o condomínio residencial e empresarial de Alphaville é um exemplo. 
superior à da urbanização presente. Já segundo Glaeser e Kahn (2004), a definição de espraiamento já está completa, se trata apenas de duas características da estrutura urbana: a descentralização e a densidade. Esses autores afirmam que haveria uma divisão ao definir o espraiamento. Os trabalhos em economia urbana tenderiam a olhar para o fenômeno a partir da discussão sobre monocentricidade e policentricidade das cidades. O espraiamento urbano estaria identificado com as cidades policêntricas: descentralizadas, mas com subcentros densificados. Contraposta a essa visão, está a da estrutura urbana descentralizada e também pouco densa, sem menção à existência ou não de subcentros. Com relação às alternativas de mensuração, Galster et al. (2001) sistematizam as dimensôes do fenômeno, indicando como medir cada uma das dimensôes - que são oito e deveriam ser levadas em conta simultaneamente: densidade, continuidade, concentração, aglomeraçáo, centralidade, nuclearidade, uso misto e proximidade.

Dessas, este estudo seguirá a ideia de Glaeser e Kahn (2004), privilegiando o estudo de concentração e densidade. A densidade é a mais explícita dentre todas as definiçóes: o espraiamento implica queda da densidade. Essa se refere à comparação da densidade residencial ou de empregos. Pode ser medida relativamente a áreas que são subdivisôes do total da cidade, comparando-se a área central com áreas distantes, por exemplo. Mas também pode ser uma medida global de toda a cidade, comparando-se diversas cidades. Ainda é possível a análise da evolução da densidade média ao longo do tempo. Já a concentração da urbanização é uma medida relativa à localização do centro da cidade. $\mathrm{Na}$ hipótese de monocentricidade a referência é o centro histórico. Já na hipótese de policentricidade a medida é feita também com relaçáo aos subcentros de emprego. Mas também levaremos em conta os vazios urbanos mencionados em Anas, Arnott e Small (1998). Portanto, definimos como espraiamento urbano o crescimento urbano que é desconcentrado, não denso e que deixa vazios urbanos dentro da mancha urbana.

\section{Forma urbana e bem-estar. O espraiamento urbano é desejável?}

A partir da revisão teórica feita acima e da motivação ao tema dada na introdução, é possível elencar os elementos que compóem o debate sobre se o espraiamento é ou não socialmente desejável. Os argumentos a favor se relacionam com o crescimento populacional impondo necessidade de mais espaço, e a preferência do morador por mais espaço individual. Já os argumentos contra giram em torno do aumento do uso de automóveis, dos impactos ao meio ambiente e dos custos de infra-estrutura.

As teorias de cidade monocêntrica colocam que a fronteira de uma cidade se caracteriza por uma disputa de usos do solo: ganha quem puder ou estiver disposto a pagar mais. Assim, quando o uso urbano "vale" mais que o uso rural, a cidade avança espacialmente. Ou seja, como argumenta Brueckner (2000), lugares que têm terra de uso rural mais valiosa, são cidades mais compactas.

Se incluirmos a densidade na análise, e imaginarmos que a escolha do tamanho da moradia e, portanto, dos lotes tem implicação direta no quão compacta a cidade é, então, uma mudança nas preferências dos consumidores já é capaz de aumentar o valor da terra urbana na fronteira da cidade. Isto se verifica, por exemplo, se a 
população passa a preferir morar em casas térreas, com jardins e piscinas. Notemos que no modelo de cidade monocêntrica mencionado anteriormente as famílias são idênticas e, portanto, escolhem o mesmo tamanho de lote em toda a cidade. Um efeito de mudança de preferências da família representativa, ou de aumento de renda, aumentaria o tamanho do lote para todas elas. Outra formulação desse modelo proposta por Fujita (1989) incorpora heterogeneidade dos agentes e determinam uma função de tamanho de lotes. Nessa formulação, de acordo com as hipóteses sobre as preferências das famílias, é possível chegar a um equilíbrio com lotes maiores na periferia, situação condizente com um crescimento urbano espraiado.

Outra perspectiva sob a qual podemos olhar o espraiamento é a da mobilidade urbana. A expansão espacial da cidade e seu menor adensamento somente são possíveis porque as tecnologias de transporte conjugam custo e tempo de maneira atraente para os moradores. Ainda dentro do tema da mobilidade urbana, podemos focar no deslocamento pendular para o trabalho. A descentralização dos empregos pode propiciar viagens mais curtas, se as famílias se mudam para locais próximos aos empregos, o que também é condizente com um contexto de crescimento urbano espraiado.

Passando para os argumentos que fazem perceber o espraiamento como indesejado, seguiremos principalmente a lógica exposta por Brueckner (2000), que indica a possibilidade de falhas de mercado no uso do solo urbano. Segundo esse autor, existiriam três fontes de falhas de mercado: o valor social do espaço aberto (de uso náo urbano), os custos sociais do congestionamento do sistema viário e os custos da infra-estrutura pública.

Tratando do valor social do espaço aberto, o problema parte da mensuração do valor da terra na zona de expansão. Do ponto de vista do proprietário da terra, seu valor corresponde à rentabilidade que essa terra lhe proporciona. No entanto, existe um valor intrínseco, social da terra que vai além daquele que o direito de propriedade individual confere ao proprietário. Em termos práticos, a terra não ocupada gera uma paisagem natural da qual não só o proprietário desfruta, mas também toda a vizinhança. Quando o proprietário decide construir sobre aquela terra, leva em conta seus benefícios particulares e seus custos particulares, e não o custo social imposto aos seus vizinhos e a toda a cidade.

A externalidade no caso dos custos de congestionamento já é bem conhecida, e trata do custo social gerado pela decisão individual em utilizar o automóvel, ocupando lugar nas vias. Ao sair com o seu carro, cada pessoa impóe às outras pessoas custos que não foram contabilizados no momento da tomada da decisão individual. Assim, seriam necessários mecanismos que fizessem o indivíduo levar em conta esse custo, internalizando a externalidade.

Já com relação à infraestrutura pública: rede de água, esgoto, iluminação pública, pavimentação de vias, etc., a externalidade surge com relação ao financiamento. É responsabilidade do governo local a provisão correta de todos esses bens a todos os moradores da cidade. Se alguns indivíduos preferem viver em densidades menores, em áreas não urbanizadas anteriormente, serão gerados mais custos que se esses indivíduos preferissem viver em densidades maiores em áreas já urbanizadas. Esses custos "extras" serão repartidos não somente entre aqueles que são seus beneficiários, 
mas entre toda a sociedade. Essa decisão individual está impondo custos sociais que financiam um benefício privado.

Cabe aqui salientar o trabalho de Ducci (1998) que descreve o caso do crescimento urbano de Santiago, no Chile. Muitos dos elementos aqui colocados no debate se o espraiamento é desejável são apontados pela autora no contexto da realidade chilena. Além disso, para o crescimento periférico de Santiago, aponta a falta de equipamentos urbanos, escolas, hospitais, comércio, transporte e como a dependência do automóvel gera mais congestionamento e poluição.

\section{Os dados}

\section{Metodologia}

Os dados utilizados provêm de fontes secundárias, que possuem informaçôes na escala intra-metropolitana. Desta maneira são utilizadas informaçóes sócio-econômicas dos Censos Demográficos de 1991 e 2000 e das Pesquisas de Origem e Destino da Companhia do Metropolitano de São Paulo de 1987, 1997 e 2007. As pesquisas oD trazem informaçôes sobre os deslocamentos urbanos: número, tempo e motivo das viagens, assim como trazem informaçôes sócio-econômicas sobre a população, como idade, escolaridade, renda e o número de empregos. Devido ao plano amostral utilizado os dados levantados são representativos no nível territorial das zonas de pesquisa, o que proporciona um retrato da distribuição espacial das variáveis internas à metrópole. No ano de 1987 são 254 zonas, em 1997 são 389 e em 2007 são 460.

A área dos setores censitários é em geral muito menor que a das zonas de origem e destino. Para os anos em que a compatibilização foi feita, o Censo de 2000 e pesquisa oD de 1997 , existem 21.744 setores censitários enquanto existem 389 zonas OD cobrindo a totalidade da área da RMSP.

Outra fonte de informaçóes essencial para a análise são os produtos cartográficos: “Mapa da Expansão da Área Urbanizada da Região Metropolitana de São Paulo" e "Mapa de Uso e Ocupaçáo do Solo da Região Metropolitana de São Paulo-2002" da Emplasa, Empresa Paulista de Planejamento Metropolitano. Utilizam-se os mapas digitalizados de evolução da área urbanizada nos períodos de 1962 até 2002, pois esses abrangem a totalidade dos municípios da Região Metropolitana de São Paulo. Cabe deixar claro que o mapa da área urbanizada de 2002 possui maior acurácia que os anteriores, pois a imagem de satélite utilizada é de alta resolução (satélite Ikonos).

A compatibilização das três fontes de dados: Censo Demográfico, Mapas Cartográficos da Emplasa e Pesquisa de Origem e Destino, foi feita através da sobreposição espacial dos mapas das unidades espaciais referentes aos dados. As três bases de dados possuem informaçóes em escalas diferentes. Escolhemos usar a escala intermediária, dos setores censitários quando analisamos as informaçôes das três bases ao mesmo tempo.

\section{As análises empíricas}

Para a mensuração empírica do fenômeno do espraiamento urbano observamos os gradientes de densidade e médias de densidades de empregos e população em três anos (1987, 1997 e 2007), construímos um índice de espraiamento, e buscamos seus determinantes na variação intra-urbana de características sócio-econômicas. 
Para estimar o gradiente de densidade de população e empregos, utilizamos análise de regressão simples, mínimos quadrados ordinários. Anas, Arnott e Small (1998) comentam como essa técnica foi bastante utilizada para documentar o que colocam como duas das mais fortes regularidades empíricas da estrutura urbana: como a densidade decai com a distância ao centro, e como quase todas as cidades do mundo desenvolvido se descentralizam durante o século xx. Nossa análise empírica mostrou que São Paulo se encaixa nesse perfil.

A análise de regressão também foi utilizada para explorar os determinantes do espraiamento urbano. Buscamos a conexão empírica com algumas variáveis socioeconômicas, uma vez que investigamos essa conexão do ponto de vista teórico. Não tentamos controlar todas as fontes de problemas na estimação, pois isto ultrapassaria o escopo deste trabalho. Mesmo assim, o exercício é válido como análise empírica exploratória do fenômeno.

Em seguida descrevemos em detalhes a construção do índice de espraiamento urbano, nossa medida empírica mais importante.

\section{A construção do Índice de Espraiamento}

O índice de espraiamento é inspirado em Burchfield, Overman, Puga e Turner (2006), e consiste na porção de área urbanizada contida em um quadrado de $1 \mathrm{~km}^{2}$ centralizado em cada um dos pontos onde é medida a urbanização. Esses pontos estão organizados em uma quadrícula, uma grelha de pontos, regular.

A quadrícula foi construída com um espaçamento de 50 metros entre os pontos. Em seguida investigamos para cada um desses pontos se o solo era ou não urbanizado sobrepondo o mapa da área urbanizada. Entáo, construímos ao redor de cada ponto um quadrado de $1 \mathrm{~km}^{2}$ de área e contamos quantos pontos "urbanizados" haviam dentro desse quadrado. Como o quadrado tem $1 \mathrm{~km}$ de lado e os pontos estão espaçados entre si 50 metros, cabem 400 pontos dentro desse quadrado de referência. Assim, o índice varia de 1 a 400. Quando o índice vale 400, o ponto no qual está sendo medido está completamente cercado de tecido urbano, tomando como referência o quadrado de $1 \mathrm{~km}^{2}$. Quando o índice vale um, o ponto urbanizado está isolado, sem nenhum outro ponto urbanizado vizinho, a mais de 50 metros e menos de 1 quilômetro de distância.

Na Figura 1 ilustramos as etapas de construção do índice para o crescimento da área urbanizada entre 1998 e 2002 . A Figura 1 (A) mostra um detalhe da mancha urbana consolidada em 1997 e o crescimento da mesma até 2002. Em seguida, na Figura 1 (B) mostramos a quadrícula de $50 \mathrm{~m}$ x 50m correspondente à área urbanizada até 2002. É com base nessa quadrícula que calculamos os valores do índice. $\mathrm{Na}$ Figura 1 (C) os tons de cinza dos pontos da quadrícula variam de acordo com o valor do índice, exclusivamente na área onde houve crescimento urbano. Valores mais altos são mais escuros. Note-se que nas bordas da mancha os valores do índice tendem para o branco, enquanto no interior tendem para o preto. Isto indica como o crescimento urbano no interior da mancha é mais compacto (valores altos do índice), e na sua borda é mais esparso (valores baixos do índice).

Essa escala de análise permite que o índice seja sensível a "buracos" dentro da área urbanizada. No mapa da mancha urbana de 2002, esses "buracos" correspondem 
aos vazios urbanos com alguma cobertura vegetal: parques, florestas ou rios e lagos. Essa característica é importante, pois dessa maneira nosso índice está captando a disputa entre os usos urbano e rural na zona de crescimento da metrópole.

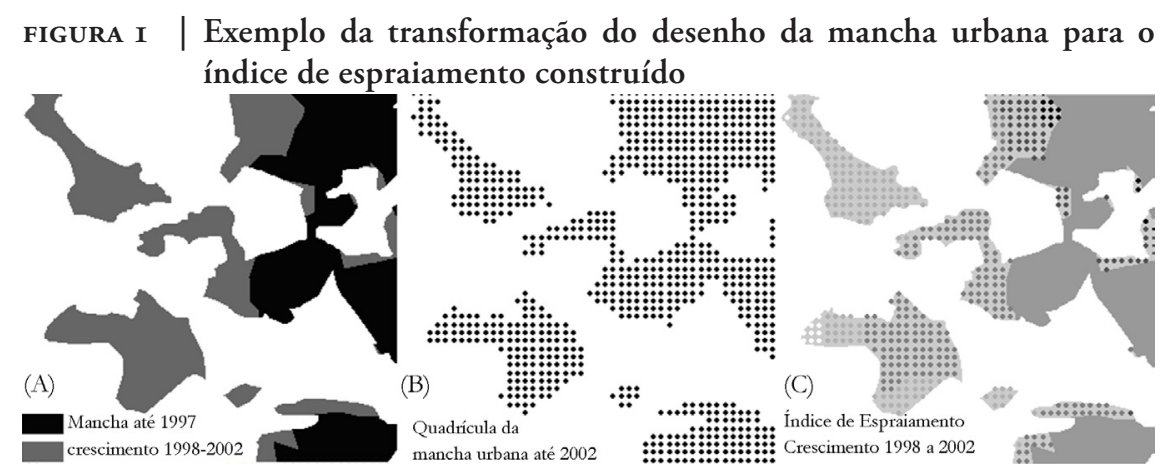

FONTE ELABORAÇÃO PRÓPRIA

Portanto, esse indicador permite descrever o fenômeno a partir do ponto de vista da definição de espraiamento que envolve a concentração, a densidade e a continuidade da área urbanizada, sem a necessidade de identificar e localizar sub-centros de emprego. Além disso, ele é interessante por trazer informaçóes em uma escala geográfica bastante detalhada, possibilitando a análise intra-urbana do fenômeno. Como a densidade, ele é sensível à escala geográfica de análise, ou seja, ao tamanho do quadrado de referência do cálculo da porção de área urbanizada. Esse tamanho e o espaçamento da quadrícula poderiam ser modificados, captando diferentes fenômenos de acordo com a escala geográfica de análise.

\section{Evoluçáo urbana em Sáo Paulo}

A característica da metrópole de São Paulo que estamos interessados em investigar, se ela é espraiada ou náo, pode ser compreendida a partir do processo de estruturação desse território. Esse, por sua vez, responde tanto a estímulos decorrentes das atividades econômicas, quanto a estímulos das políticas públicas implementadas.

A grande mudança recente, na estruturação urbana da metrópole, foi a predominância de empregos na cidade de São Paulo no setor terciário. Como colocado em Biderman (2001), essa nova atividade econômica se beneficia mais de ganhos de urbanização. Segundo Meyer, Grostein e Biderman (2004), isto renova a distribuição funcional dos municípios da região e provoca mudanças na utilização do espaço. A nova função de serviços especializados para consumidores e firmas se concentra no município de São Paulo. Ela provoca a necessidade de novos espaços, mais modernos, incitando a desconcentração das funções centrais.

Em geral, esse movimento intraurbano reforça o padrão periférico de urbanização, no qual a porçáo central da metrópole perde populaçáo, enquanto a mancha urbana continua crescendo. O poder público, por sua vez, não só corrobora como também é indutor desse padrão, pois constrói conjuntos de habitação popular em zonas muito afastadas do centro, e permite a invasão de áreas desocupadas nas franjas da cidade. 
Assim, as populaçôes de menor renda paulatinamente passam a morar nas periferias por três razóes. A disponibilidade de terrenos que pudessem ser ocupados de forma irregular (mais intenso na regiáo sul). A oferta pública de grandes conjuntos habitacionais a partir da década de 1960 (mais intenso na regiáo leste), o que também estimulou a autoconstrução na periferia devido à oferta de lotes urbanizados de baixo preço. $\mathrm{Na}$ década de 1980 o movimento para a periferia também se intensifica nas camadas de maior poder aquisitivo que buscam os condomínios fechados (Meyer et al., 2004).

Taschner e Bógus (2001) também identificam a reestruturação dos processos produtivos e mudanças sócio-ocupacionais no espaço intrametropolitano paulista. Estas autoras apontam como o padrão de crescimento demográfico é periférico mas adicionam a esta análise o perfil ocupacional das camadas sociais. Identificam a desigualdade social como efeito da globalização, mas qualificam essa desigualdade no espaço como "espaços fortemente segregados, onde a presença seja da populaçáo de alta renda e alta qualificação profissional, seja de população de baixa renda e precária qualificação para o trabalho, é pouco permeada por elementos de outras camadas sociais". (Taschner \& Bógus, 2001, p. 112). Essa segregação aconteceria também na periferia.

A infraestrutura urbana é um ponto-chave na evolução do espraiamento. Necessariamente a conversão de terra rural em terra urbana implica provisão de infraestrutura urbana. Mas é o poder público que tem a incumbência de fazê-lo e é a totalidade da sociedade que paga por ela. No caso brasileiro e, em particular, de Sáo Paulo, como é a população de menor poder econômico que predominantemente ocupa as zonas periféricas, e muitas vezes em caráter irregular, esta provisão é lenta, insuficiente, na medida em que essa população de menor renda tem menor poder político. Como exemplo dessa situação, a Figura 2 ilustra os dez piores municípios em proporção de domicílios conectados à rede pública de água ou de esgotamento sanitário para o ano 2000, todos na periferia da RMSP.

FIGURA 2 Localização dos municípios da RMSP com menos domicílios conectados à rede de água e/ou rede pública de esgoto no ano 2000

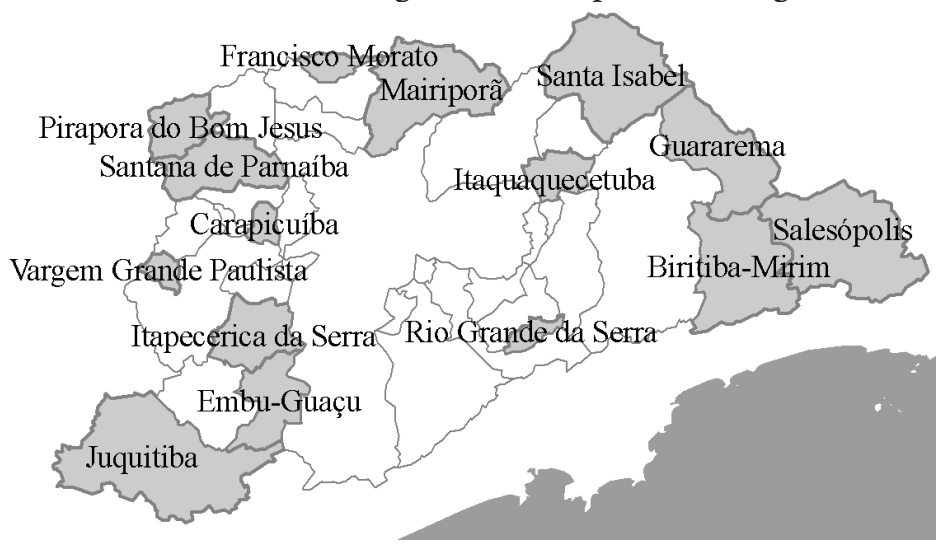

FONTE ELABORAÇÃO PRÓPRIA. 


\section{Houve espraiamento urbano em Sáo Paulo?}

\section{Estimação dos gradiente de densidade}

Segundo Anas, Arnott e Small (1998), o padrão de distribuição das densidades populacional e de empregos pode ser aproximado por uma função exponencial negativa da seguinte maneira:

$$
D(k)=D_{0} e^{-D_{1} k}
$$

Onde k é a distância ao centro, $\mathrm{D}(\mathrm{k})$ é a densidade em função da distância ao centro, $\mathrm{D}_{0}$ é a densidade no centro e $\mathrm{D}_{1}$ é o gradiente de densidade. Esta função pode ser estimada utilizando-se uma regressão linear simples, aplicando o logaritmo natural para os dados disponíveis para cada zona origem-destino. Em seguida apresentamos os resultados:

TABELA I | Estimativas do gradiente de densidade

\begin{tabular}{|l|c|c|c|c|}
\hline TIPO DE DENSIDADE & ANO & GRADIENTE & $\begin{array}{c}\text { DENSIDADE NO } \\
\text { CENTRO }\end{array}$ & R2 \\
\hline Empregos & 1987 & 0,212 & 3.159 & 0,471 \\
\hline Empregos & 1997 & 0,149 & 8.171 & 0,311 \\
\hline Empregos & 2007 & 0,125 & 21.634 & 0,652 \\
\hline Populacional & 1987 & 0,144 & 10.353 & 0,616 \\
\hline Populacional & 1997 & 0,114 & 8.935 & 0,249 \\
\hline Populacional & 2007 & 0,064 & 16.155 & 0,359 \\
\hline
\end{tabular}

FONTE ELABORAÇÃO PRÓPRIA A PARTIR DOS DADOS DAS PESQUISAS DE ORIGEM E DESTINO COMPANHIA DO METROPOLITANO DE SÃo PAULO

Todos os gradientes estimados decrescem ao longo dos três anos. Eles são estatisticamente significantes com um nível de significância de 1\%. Em todos os períodos a inclinação da função de densidade dos empregos é maior que a populacional. Assim, tanto empregos como residências estão se desconcentrando. Por outro lado, os empregos permanecem mais concentrados que as residências. Os gradientes cada vez menores indicam que a fronteira urbana está cada vez mais longe.

TABEla 2 Médias das densidades de empregos e populacional nas zonas de origem-destino

\begin{tabular}{|l|c|c|c|}
\cline { 3 - 4 } \multicolumn{2}{c|}{} & DENSIDADE POPULACIONAL & DENSIDADE DE EMPREGOS \\
\hline \multirow{3}{*}{ ANO } & 1987 & 7.511 & 4.762 \\
\cline { 2 - 4 } & 1997 & 9.918 & 5.133 \\
\cline { 2 - 4 } & 2007 & 8.684 & 8.177 \\
\hline
\end{tabular}

FONTE ELABORAÇÃO PRÓPRIA A PARTIR DOS DADOS DAS PESQUISAS DE ORIGEM E DESTINO COMPANHIA DO METROPOLITANO DE SÃo PAULO

As médias das densidades populacional e de empregos das zonas origem e destino, apresentadas na tabela 2, complementam as informaçóes dos gradientes de densidade. $\mathrm{O}$ aumento constante da média das densidades de empregos indica como estes 
estão se concentrando em algumas zonas origem-destino. Já a queda da densidade média populacional entre 1997 e 2007 indica desconcentração da população nesse período, condizente com a dispersão residencial e espraiamento urbano no período. Portanto, a queda dos gradientes de densidade de empregos e populacional e a queda da densidade populacional no período 1997-2007 são medidas empíricas que descrevem o crescimento urbano da RMSP como espraiado.

\section{Índice de espraiamento do crescimento da mancha urbana}

Para identificar mais detalhadamente o fenômeno do espraiamento urbano, passamos a relatar o resultado da mensuração do índice de espraiamento proposto, exclusivamente na parte da cidade onde houve crescimento da mancha urbana para os seis períodos de crescimento disponíveis. Através desse índice, medimos se o tecido urbano cresceu de forma mais ou menos compacta. Como mencionado anteriormente, na borda da mancha urbana o índice é menor, assim como no interior da mancha urbana o índice é maior.

\section{GRÁfICO I | Evolução dos índices de espraiamento e do crescimento da área urbanizada}

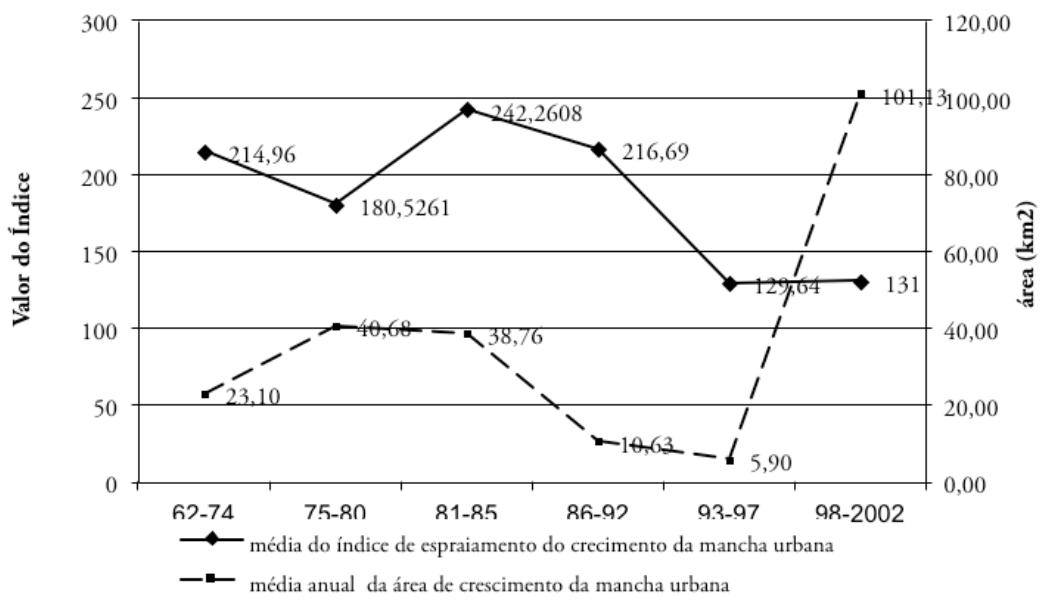

FONTE ELABORAÇÃO PRÓPRIA

Apresentamos, no Gráfico 1, a evolução do índice calculado para o crescimento da mancha urbana e a média anual do crescimento da área urbanizada. O índice do período 1981-1985 (242) cresceu com relação ao período 1975-1980 (180). Esse é o único comportamento de crescimento compacto, que preenche vazios urbanos, ao longo de todo o período estudado. Os outros períodos aparentam uma queda do índice, ou seja, crescimento urbano mais disperso. Já com relação à área média de crescimento da mancha urbana, após 1974 há uma tendência de crescimento cada vez menor em área. $\mathrm{O}$ aumento muito grande na média anual do crescimento da área urbanizada para o último período é justificada pela utilização de foto de 
satélite mais detalhada em 2002, que capta menores áreas urbanizadas antes não identificadas. Assim, a mensagem que extraímos é que a partir de 1985 o crescimento urbano que aconteceu em menor quantidade foi também se organizando de maneira cada vez mais esparsa na fronteira da metrópole. Portanto, esse período mais recente é compatível com o fenômeno de espraiamento urbano.

\section{Os determinantes do espraiamento}

\section{Descrição das variáveis utilizadas}

Neste exercício empírico a variável explicada, oriunda dos mapas de expansão da área urbanizada da Emplasa, é a média do índice de espraiamento mencionado na seção anterior, calculada dentro dos setores censitários de 2000. Utilizamos como variáveis explicativas as informaçóes tanto das pesquisas oD do metrô quanto do Censo Demográfico 2000. Apresentamos, na Figura 3, o mapa do valor do índice para cada um dos pontos onde ele foi calculado, no período de 1998 a 2002. Note-se como os valores mais altos estão próximos da borda da área urbanizada até o ano de 1997, o ano imediatamente anterior ao crescimento considerado.

FIgURA 3 | Valores do índice de espraiamento. Crescimento da área urbanizada entre 1998 e 2002

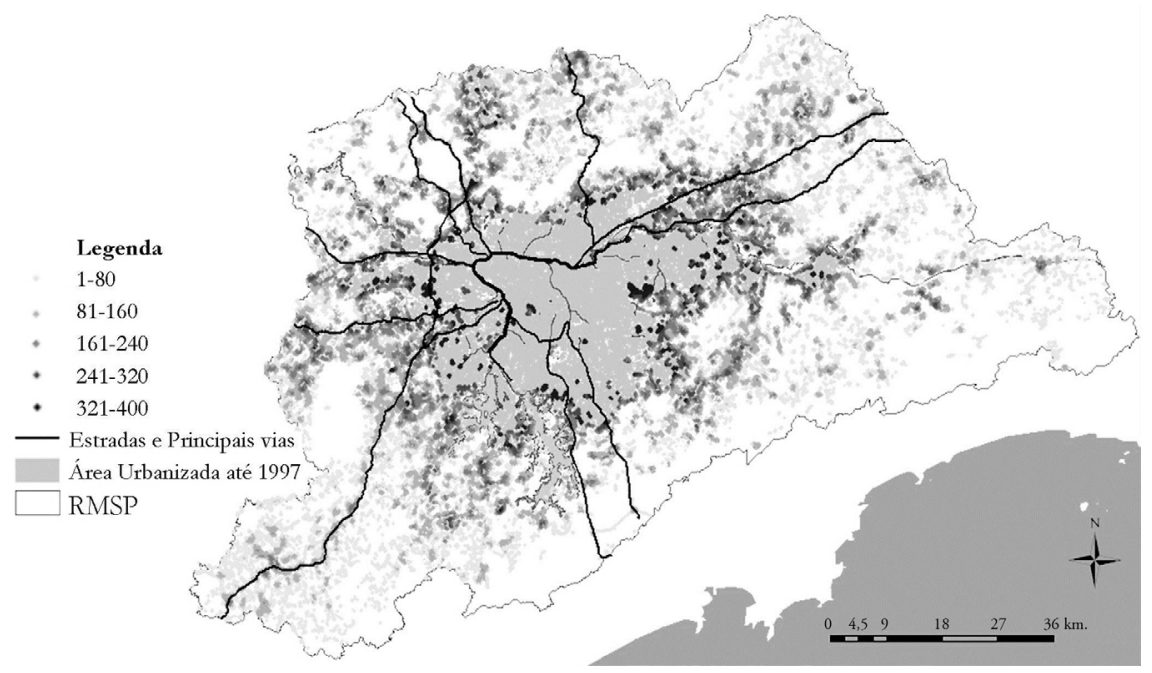

FONTE ELABORAÇÃO PRÓPRIA

Passamos a analisar as variáveis utilizadas. A superposição do mapa de crescimento da mancha urbana entre 1998 e 2002 e o mapa de setores censitários indicou os setores onde houve crescimento urbano (periferia), apenas 1,5\% do total. Apresentamos, na Tabela 3, as estatísticas descritivas das variáveis dependentes e independente para esses setores e para os setores correspondentes à mancha urbana de 1997. Esses dados formam um bom retrato da porção da metrópole que estamos estudando. 
TABELA 3 Estatísticas descritivas das variáveis dependentes e independente

\begin{tabular}{|c|c|c|c|c|c|c|c|c|}
\hline & \multicolumn{4}{|c|}{ SETORES DA MANCHA ATÉ I 997} & \multicolumn{4}{|c|}{$\begin{array}{c}\text { SETORES EM QUE HOUVE } \\
\text { CRESCIMENTO DA MANCHA ENTRE } \\
\text { I998 E } 2002\end{array}$} \\
\hline & MÉDIA & MEDIANA & MínIMo & MÁXIMO & MÉDIA & MEDIANA & MÍNIMO & MÁximo \\
\hline Índice de Espraiamento & 105 & 93 & 9 & 347 & 225 & 225 & 8 & 400 \\
\hline Distância à Sé (km) & 15,6 & 15,2 & 0,1 & 80,3 & 27,2 & 25,1 & 3,1 & 88,6 \\
\hline $\begin{array}{l}\text { Densidade de Empre- } \\
\text { gos }\left(\mathrm{km}^{2}\right)\end{array}$ & 52 & 30 & 0 & 1.371 & 11 & 6 & 0 & 202 \\
\hline $\begin{array}{l}\text { Viagens produzidas por } \\
\text { modo coletivo }\end{array}$ & 44.154 & 33.512 & 0 & 144.496 & 35.629 & 28.112 & 289 & 144.496 \\
\hline $\begin{array}{l}\text { Viagens produzidas por } \\
\text { modo individual }\end{array}$ & 43.161 & 28.469 & 0 & 215.202 & 28.241 & 17.367 & 20 & 215.202 \\
\hline $\begin{array}{l}\text { Viagens produzidas por } \\
\text { modo a pé }\end{array}$ & 55.364 & 38.265 & 0 & 272.776 & 55.982 & 38.101 & 57 & 272.776 \\
\hline $\begin{array}{l}\text { Média de automóveis } \\
\text { por domicílio }\end{array}$ & 0,74 & 0,67 & 0,12 & 2,31 & 0,57 & 0,55 & 0,20 & 2,31 \\
\hline $\begin{array}{l}\text { Densidade de Domicí- } \\
\text { lios }\left(\text { domicílios } / \mathrm{km}^{2} \text { ) }\right.\end{array}$ & 9.394 & 4.503 & 0 & 812.196 & 2.760 & 1.252 & 0 & 204.639 \\
\hline $\begin{array}{l}\text { \% de domicílios abas- } \\
\text { tecidos com água da } \\
\text { rede geral }\end{array}$ & $98,2 \%$ & $100,0 \%$ & $0,0 \%$ & $100,0 \%$ & $82,0 \%$ & $98,3 \%$ & $0,0 \%$ & $100,0 \%$ \\
\hline $\begin{array}{l}\text { \% de domicílios com } \\
\text { esgotamento sanitário } \\
\text { via rede geral }\end{array}$ & $86,7 \%$ & $99,2 \%$ & $0,0 \%$ & $100,0 \%$ & $49,8 \%$ & $54,4 \%$ & $0,0 \%$ & $100,0 \%$ \\
\hline \begin{tabular}{|l|} 
Renda média do res- \\
ponsável (reais de julho \\
de 2000)
\end{tabular} & 1.248 & 798 & 47 & 18.876 & 703 & 496 & 34 & 16.480 \\
\hline
\end{tabular}

FONTE ELABORAÇÃo PRÓPRIA

A média do índice de espraiamento nos setores onde houve crescimento urbano são muito inferiores às dos setores da mancha de 1997, indicando como a nova ocupação urbana é menos compacta que a consolidada.

Com relação às viagens por modo, tanto para a periferia quanto para a mancha consolidada as viagens por modo coletivo são em média superiores às de modo individual. No entanto, na mancha consolidada as viagens por modo coletivo são ligeiramente superiores enquanto na zona de expansão urbana a média é mais de $60 \%$ maior que as viagens por modo individual. Da mesma maneira, há menos automóveis por domicílio que para os setores da mancha de 1997. Ou seja, a populaçáo ocupando a periferia se desloca menos de automóvel que a população da mancha consolidada.

Surpreende como a densidade de domicílios dos setores da expansão urbana é muito maior que da mancha consolidada. Com relação à extensão da rede de água e esgoto, é curioso como a rede de esgoto cobre uma proporção muito menor de setores que a de água, além de ser muito inferior à da mancha consolidada.

Analisando a renda média do responsável pelo domicílio, a amplitude é semelhante entre os dois grupos de setores. Como as medianas são menores que as médias, há evidências de concentração de renda nas classes de renda superiores. Mesmo assim, a renda é consideravelmente menor na franja de expansão metropolitana. 
Olhando mais de perto para a distribuição da renda identificamos os setores censitários do decil inferior de renda e os do decil superior de renda considerando os dois conjuntos de setores ao mesmo tempo, tanto os da franja periférica, quanto os da mancha consolidada. O limiar de renda média do decil superior é de 2.464 reais de 2000, enquanto que o limiar do decil inferior de renda é 367 reais de 2000. De um total de 21.495 setores 3.424 (16\%) estão na zona de expansão urbana. Mas, dos setores do decil inferior de renda 33\% estão na zona de expansão urbana e dos setores do decil superior apenas $4 \%$ estão neste grupo. Ou seja, há proporcionalmente mais pobres na franja de expansão urbana e menos ricos. Esmiuçando a distribuição espacial da renda apresentamos, na Figura 4, a localização desses setores. Notamos como a expansão urbana acontece de forma mais generalizada pelas classes mais pobres, enquanto pela classe mais rica acontece de forma mais concentrada. Cabe notar especificamente a ocupação de alta renda na porção Noroeste da metrópole, onde se concentram condomínios fechados já mencionados no texto.

FIGURA 4 Decil superior e inferior da renda média do chefe do domicílio em 2000. Setores censitários em que houve crescimento da mancha urbana entre 1998 e 2002

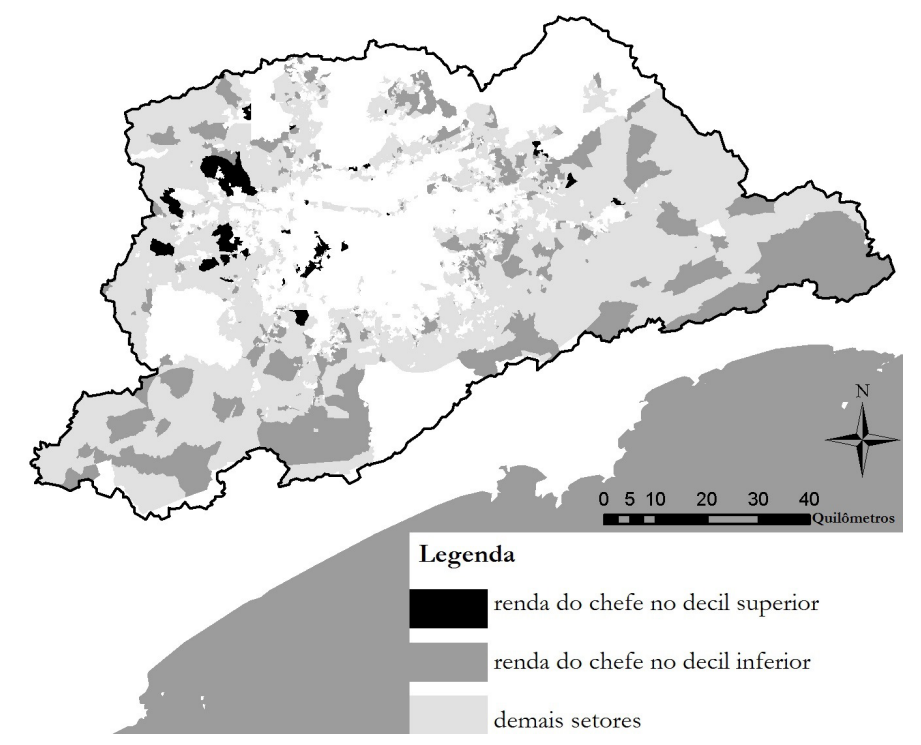

FONTE ELABORAÇÃo PRÓPRIA

Com relação à variável de setores censitários subnormais ${ }^{7}$, indicando se o setor é ou não subnormal, $9,55 \%$ dos setores em questão são subnormais, proporção muito semelhante à totalidade dos setores da mancha consolidada, de 9,42\%. Neles

7 A definição de aglomerado subnormal do IBGE: "É o conjunto constituído por um mínimo de 51 domicílios, ocupando ou tendo ocupado, até período recente, terreno de propriedade alheia (pública ou particular), dispostos, em geral, de forma desordenada e densa, e carentes, em sua maioria, de serviços públicos essenciais”. 
encontramos a população de baixa renda: verificamos que a média da renda média mensal do responsável nos setores subnormais é de 332 reais de 2000, bem menor que nos demais setores, de 742 reais de 2000.

Em resumo, este retrato é condizente com a seguinte descrição da periferia da metrópole: onde há ocupação apresenta alta densidade domiciliar, mas com poucos empregos e com infra-estrutura urbana insuficiente. Viaja-se pouco de carro, pois a renda é abaixo da média. Mas a desigualdade de renda é grande, com alguns locais de alta renda, os condomínios fechados. Há menos ricos na periferia que na mancha urbana consolidada.

\section{Estimação econométrica dos determinantes do espraiamento}

Como estratégia de controle de endogeneidade seguimos Burchfield et al. (2006), utilizando as medidas das características no período inicial como determinantes do índice de espraiamento do crescimento da área urbanizada. A escolha do período analisado foi feita com base na disponibilidade dos dados, pois somente tivemos acesso ao mapa de setores censitários do ano de $2000^{8}$. Assim, utilizamos as informaçóes das pesquisas od de 1997 e do Censo Demográfico de 2000 como descritores do período inicial. Por outro lado, o período de crescimento da mancha urbana considerado foi o de 1998 a 2002. Devemos considerar o período de crescimento de 1998 a 2002 como suficientemente desconectado das condiçóes iniciais do Censo de 2000. Isto enfraquece uma correlação direta entre o que aconteceu no período de 1998-2002, com as características da área em 2000, viabilizando nossa estratégia de controle de endogeneidade.

Os resultados da regressão são apresentados na Tabela 4. A escolha dos determinantes se confirmou como apropriada, pois somente duas variáveis não são estatisticamente significantes. Dentre os determinantes encontramos aqueles corroborando o modelo de cidade monocêntrica, e aqueles que não estão de acordo com as hipóteses desse modelo. Os determinantes em sintonia com o modelo de cidade monocêntrica podem ser divididos em dois blocos. O primeiro reunindo as variáveis mensurando a proximidade a centros ou subcentros (distância ao centro e as densidades). O segundo, relativo às variáveis de mobilidade urbana (aproximaçóes dos custos de transporte). Já com relação a determinantes que não estão de acordo com as hipóteses do modelo de cidade monocêntrica temos um bloco de variáveis captando a heterogeneidade dos agentes (renda e característica subnormal do setor), além de um bloco de variáveis que captam a presença de infra-estrutura (água e esgoto). Estas características náo estão de acordo com a hipótese do modelo AMM que diz que o suporte físico da cidade deve ser espacialmente homogêneo em suas características. Em seguida comentamos os resultados de acordo com cada bloco de variáveis.

Com relação à proximidade de centros ou subcentros, a significância e o sinal do coeficiente da variável distância à Sé confirmam o poder explicativo do modelo de cidade monocêntrica. Esse é um resultado esperado, pois nosso índice de espraiamento é também uma medida de densidade, que segundo o modelo AMM cai quanto maior da distância do centro de negócios. Além disso, esta regularidade empírica 
também é captada pela nossa estimação do gradiente de densidades apresentada anteriormente.

Já as variáveis: densidade de empregos e densidade de população, com seus sinais positivos, podem ser interpretadas como indicando a coexistência da cidade monocêntrica com a policêntrica. $O$ centro histórico permanece importante, mas existem outros subcentros também importantes. Pela definição de um centro, este possui maior concentração de empregos. Por sua atratividade, quanto menor a distância a ele, maior a densidade populacional. Assim, ambas as variáveis podem ser vistas como medindo a proximidade a subcentros, o que explica os impactos positivos no índice de espraiamento.

TABELA 4 Determinantes do índice de espraiamento do crescimento da mancha urbana entre 1998 e 2002

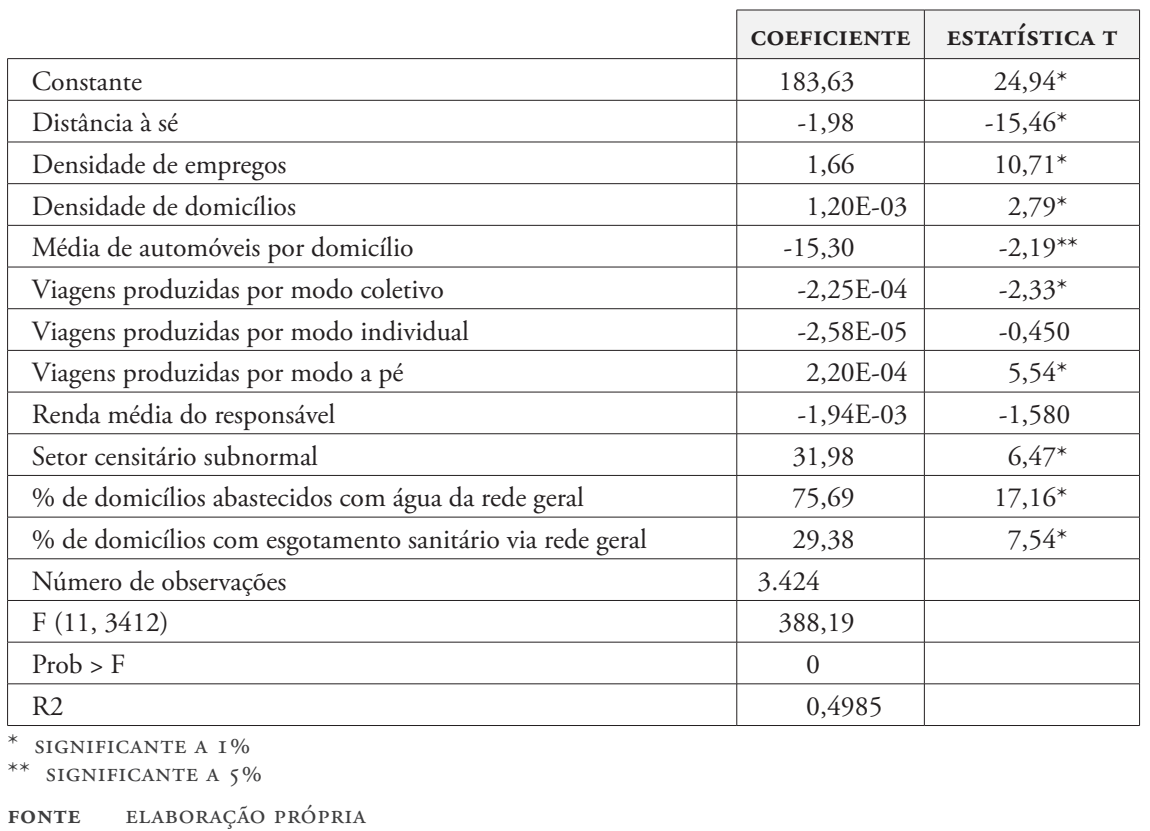

O bloco com variáveis relacionadas à mobilidade urbana das áreas com crescimento urbano também é analisado à luz do modelo AMM. Estas variáveis são fundamentais no contexto de nossa análise, pois o automóvel é causador de poluição atmosférica e congestionamentos, além de ser apontado como grande causador do espraiamento urbano em Glaeser e Kahn (2004), assim como em Burchfield et al. (2006).

No modelo AMM, mudanças nos custos de transportes têm impacto sobre a fronteira da cidade e a densidade. Um aumento nos custos marginais de transporte implica na fronteira da cidade mais próxima ao centro e rotação no sentido horário da função de densidade. Ou seja, no nosso caso, diminuiria o índice de espraiamento para o crescimento da mancha urbana. 
Desta forma, é interessante que a variável "média de automóveis por domicílio" tenha um coeficiente negativo. Ela constata que de fato a possibilidade de se locomover em automóvel implica em um crescimento urbano mais esparso, como dizem as teorias em que o automóvel é o causador do espraiamento urbano. No contexto do modelo AMM, podemos considerar o modo de deslocamento via automóvel como mais custoso que os demais modos, justificando o impacto negativo no índice.

Em seguida apresentamos os resultados para as variáveis que medem o total de viagens produzidas por modo de deslocamento. O total de viagens por modo individual não é significante, apesar da significância da variável referente à média de automóveis por domicílio. Já as variáveis relativas aos deslocamentos via modo coletivo e a pé são significantes, passamos a interpretar seus coeficientes. Consideramos que o que diferencia o impacto desses modos de deslocamento é o custo de transporte. As viagens à pé são menos custosas, em termos monetários, que as viagens por modo coletivo. Portanto, justifica-se que o impacto dessa variável no índice de espraiamento seja positivo, enquanto a variável que mede o total de viagens do modo coletivo tem impacto negativo. Outra característica relativa às viagens por modo coletivo na RMSP é que as tarifas são únicas, não variam de acordo com o comprimento das viagens. Portanto, são um estímulo à ocupação de terras mais distantes, ainda atendidas por alguma linha de ônibus. Esse fato ajuda a explicar que zonas onde se usa mais o transporte coletivo apresentem crescimento urbano menos compacto.

Deixamos de lado o arcabouço do modelo AмM, apresentando o impacto das variáveis que indicam a heterogeneidade dos habitantes na RMSP, quais sejam, a renda média do responsável e o fato do setor ser subnormal ou não. A análise das estatísticas descritivas feita anteriormente nos mostra como estas variáveis indicam as duas possibilidades de ocupação da periferia identificadas na análise do histórico da cidade. Por um lado a população de menor renda, em busca de opçóes baratas de moradias, por outro a população de alta renda em busca de condomínios fechados. Devido às restriçôes orçamentárias, a ocupação da população de baixa renda é mais compacta que a da população de alta renda.

A dummy da subnormalidade indica o aumento de 32 unidades no índice de espraiamento, esta variável sinaliza a ocupação do solo de forma ilegal, sem deixar espaçamentos mínimos entre as edificaçôes. Favelas, por definição, são muito densas. O sinal da variável de renda é coerente com a hipótese de ocupação menos compacta (índice de espraiamento baixo) das populaçóes de maior renda em condomínios fechados. No entanto, essa variável não é estatisticamente significante, portanto, não podemos confirmar empiricamente a conexão entre alta renda e ocupaçáo menos densa da área urbana.

Entrando na interpretação das variáveis que medem a rede de infra-estrutura urbana de abastecimento de água e rede de esgoto, vemos que ambas variáveis possuem um impacto positivo no índice. Um aumento de 100\% de domicílios atendidos por rede de água aumenta o índice em 75 pontos enquanto um aumento de $100 \%$ na rede de esgoto aumenta o índice em 29 pontos. Como esse impacto acontece a partir de condiçóes iniciais sobre o crescimento urbano, isso significa que lugares com maior provisão de infraestrutura atraem crescimento mais compacto que lugares com menor infraestrutura. Como vimos na teoria, a urbanização de zonas 
mais afastadas da cidade implica em custos de infraestrutura que serão bancados pelos contribuintes da cidade inteira. Esse impacto também pode ser interpretado à luz dos resultados do modelo de Henderson e Mitra (1996), que também menciona que menores custos de infraestrutura estimulam a urbanização, no seu caso, sob a forma de novos centros de emprego.

\section{Conclusóes}

A partir da nossa definição de espraiamento urbano: a área urbanizada cada vez menos concentrada, menos densa e com mais vazios urbanos, elencamos os principais resultados da análise, para concluir se houve ou náo espraiamento urbano na RMSP. Complementarmente, retomamos os principais esclarecimentos com relação aos seus determinantes, que nos permitem explorar os vínculos com os problemas urbanos que nos serviram de motivação: os congestionamentos, a vulnerabilidade ambiental e a desigualdade sócio-espacial.

Cabe destacar o grande esforço feito no sentido de encontrar uma medida empírica do fenômeno do espraiamento urbano. Ressaltamos que o índice proposto satisfaz esse objetivo, pois, leva em conta os três aspectos do fenômeno. É sensível a vazios urbanos, é medido em escala geográfica suficientemente detalhada e, ao ser medido apenas na parte da área urbanizada em que houve crescimento urbano, leva em conta a desconcentração populacional. Por outro lado, o fato de se utilizar uma mesma quadrícula de pontos para traduzir as informaçóes dos mapas de área urbanizada dos diferentes anos permitiu a comparação temporal e análise da evolução urbana.

Com relaçáo à densidade média das zonas oD, houve a queda da densidade populacional no período 1997 a 2007. Por outro lado, a análise dos gradientes de densidade indicou uma tendência à desconcentração tanto de população quanto de empregos. A análise da média dos índices de espraiamento urbano calculados na franja de crescimento urbano passa a cair somente a partir do período 1981 a 1985 em diante. Portanto, concluímos que houve espraiamento urbano na RMSP, porém não em todo o período estudado (1962 a 2002), mas apenas no crescimento urbano mais recente.

Passando para as causas do espraiamento, foram possíveis análises interessantes relativas aos efeitos das diferenças dos custos de transporte de diferentes modalidades de deslocamento. Destaca-se a inserção das causas do espraiamento no contexto do processo de periferização da populaçáo pobre e opção das classes altas por condomínios fechados. Os determinantes encontrados e a análise de seu impacto indicam que esse fenômeno acontece principalmente a partir da ocupação da periferia urbana pelas classes de renda inferiores. A análise da provisão de infraestrutura para essa periferia de qualidade de vida precária coloca o poder público num círculo vicioso: pois quanto mais disponibilidade de infra-estrutura também maior será o "espalhamento" da área urbanizada.

Essas conclusôes mostram a urgência de alternativas habitacionais populares na parte já consolidada da cidade. Nesses lugares os investimentos em equipamentos públicos e infra-estrutura já estão feitos, há menos necessidade de automóvel, que causa congestionamentos e evita-se o uso de áreas de cobertura vegetal nativa que deveriam ser preservadas. 


\section{Referências bibliográficas}

Alonso, W. (1964). Location and Land Use. Cambridge: Harvard University Press.

Anas A., Arnott, R. \& Small, K. (1998). Urban spatial structure. Journal of Economic Literature, $36,1426-1464$.

Biderman C. (2001). Forças de atração e expulsão na Grande São Paulo. Tese de Doutorado, Escola de administração de empresas, Fundação Getúlio Vargas, São Paulo.

Brueckner, J. (1987). The structure of urban equilibria: A unified treatment of the muth-mills model. Em E. Mills, Handbook of Regional and Urban Economics (vol. 2, cap. 20, pp. 821-845). Amsterdam: North Holland.

Brueckner, J. (2000). Urban sprawl: diagnosis and remedies. International Regional Science Review, 23(2), 160-171.

Burchfield, M., Overman, H., Puga, D. \& Turner, M. (2006). Causes of sprawl: A portrait from space. Quarterly Journal of Economics, 121(2), 587-633.

Ducci, M.E. (1998). Santiago, ¿una mancha de aceite sin fin? ¿Qué pasa con la población cuando la ciudad crece indiscriminadamente? EURE, 24(72), 85-94. http://dx.doi. org/10.4067/S0250-71611998007200005

Fujita M. (1989). Urban Economic Theory. Cambridge: Cambridge University Press.

Fujita, M. \& Ogawa, H. (1982). Multiple equilibria and structural transition of nonmonocentric urban configurations. Regional Science and Urban Economics, 12(2), 161196. doi: 10.1016/0166-0462(82)90031-X

Galster, G., Hanson R., Ratcliffe M., Wolman, H., Coleman, S. \& Freihage, J. (2001). Wrestling sprawl to the ground: defining and measuring an elusive concept. Housing Policy Debate, 12(4), 681-717. doi: 10.1080/10511482.2001.9521426

Glaeser, E. \& Kahn, M. (2004). Sprawl and urban growth. In: H. Henderson \& J. Thisse, Handbook of Regional and Urban Economics (vol. 4, cap. 56, pp. 2481-2527). Amsterdam: North Holland.

Henderson, V. \& Mitra, A. (1996). The new urban landscape: Developers and edge cities. Regional Science and Urban Economics, 26(6), 613-643. Disponível em http://down. cenet.org.cn/upfile/49/2005102815445145.pdf

Instituto Brasileiro de Geografia e Estatística (IBGE). (2011). Censo 2010: Tabela 1309, população residente por sexo, situaçấo e localização da área. Acessado em 03 de maio de $2013 \mathrm{em}$ http://www.sidra.ibge.gov.br/bda/tabela/protabl.asp?c=3145\&z=cd\&o=6\&i=P

Instituto Nacional de Estadística y Geografía (INEGI). (2011). Cuaderno Estadístico de la Zona Metropolitana del Valle de México. Acessado em 03 de maio de 2013 em http://www. inegi.org.mx/est/contenidos/espanol/sistemas/cezm11/estatal/default.htm

Knaap, G. \& Talen, E. (2005). New urbanism and smart growth: a few words from the academy. International Regional Science Review, 28(2), 107-118. doi: $10.1177 / 0160017604273621$

Maricato, E. (2001). Moradia social e meio ambiente. Sinópses (FAUUSP), (35), 54-69.

Meyer, R., Grostein, M. \& Biderman, C. (2004). São Paulo Metrópole. São Paulo: Editora da Universidade de São Paulo-Imprensa Oficial do Estado de São Paulo.

Mills, E. (1967). An aggregative model of resource allocation in a metropolitan area. American Economic Review, 57(2), 197-210. Disponível em http://www.vwl.tuwien.ac.at/ hanappi/AgeSo/rp/Mills_1967.pdf 
Mills, E. (1972). Studies in the Structure of the Urban Economy. Baltimore, MD: Johns Hopkins University Press.

Muth, R. (1969). Cities and Housing. Chicago, IL: University of Chicago Press.

Prefeitura do Município de São Paulo. (2002). Atlas Ambiental do Município de São Paulo. São Paulo: Secretaria Municipal do Meio Ambiente, Secretaria Municipal de Planejamento Urbano.

Taschner, S.P. \& Bógus, L.M.M. (2001). São Paulo, uma metrópole desigual. EURE, 27(80), 87-120. http://dx.doi.org/10.4067/S0250-71612001008000005 
